\title{
Hyposensitization in nickel allergic contact dermatitis: Clinical and immunologic monitoring
}

\author{
Roger J. J. Troost, MD, ${ }^{a}$ Martina M. A. Kozel, MD, ${ }^{\mathrm{b}}$ Cornelia G. van Helden-Meeuwsen, ${ }^{\mathrm{b}}$ \\ Theodoor van Joost, ${ }^{a}$ Paul G. H. Mulder, $\mathrm{PhD},{ }^{\mathrm{c}}$ Robbert Benner, ${ }^{\mathrm{b}}$ and \\ Errol P. Prens, MD, $\mathrm{PhD}^{\mathrm{b}}$ Rotterdam, The Netherlands
}

\begin{abstract}
Background: In allergic contact dermatitis (ACD) previously sensitized T cells cause skin damage. If an ubiquitous allergen such as nickel is involved, no effective treatment is available. Down-regulation of this allergic response has been described after antigen presentation in the absence of adequate costimulatory signals. UV exposure can enhance such hyposensitization.

Objective: The aim of this study was to establish the capability of a hyposensitization procedure to induce antigen-specific tolerance.

Methods: Twenty-one patients with nickel ACD were randomly assigned to either a hyposensitized or control group. A schedule consisting of UVB treatment and subcutaneous nickel sulfate administration (hyposensitization) or UVB only (control) was applied. During the ensuing 2 years, several clinical and immunologic features were monitored.

Results: During UVB treatment we observed a significant clinical improvement in both groups that persisted in the hyposensitized group. Except for increased slope variances of specific lymphocyte proliferation in time, no clear changes were seen in the immunologic findings.

Conclusion: Despite significant clinical improvement induced by UVB, hyposensitization did not induce significant changes in the immunologic findings in patients with nickel ACD.

(J Am ACAD DeRmatol 1995;32:576-83.)
\end{abstract}

The type of allergic contact dermatitis (ACD) most frequently diagnosed involves nickel allergy. Treatment of chronic ACD has been largely symptomatic because consistent avoidance of skin contact with and dietary intake of nickel are difficult to achieve. Allergen-specific Tlymphocytes are crucial in the pathogenesis of ACD. Nickel-specific T lymphocyte clones have been isolated from peripheral blood of nickel-allergic patients. ${ }^{1-4}$ When activated, these $\mathrm{T}$ lymphocytes produce interleukin 2 (IL-2) and high levels of interferon- $\gamma^{1,4}$ and cause inflammatory skin injury. Prevention of skin injury may be obtained through inhibition of specific T-cell activation (e.g., through hyposensitization).

A state of specific tolerance or anergy has been

From the Departments of Dermatology, ${ }^{a}$ Immunology, ${ }^{b}$ and Biostatistics, ${ }^{c}$ Erasmus University and University Hospital Dijkzigt.

Supported by grant 002818170 from the Praeventiefonds.

Accepted for publication Nov. 7, 1994.

Reprint requests: Roger J. J. Troost, MD, Department of Immunology, Erasmus University, P.O. Box 1738, 3000 DR, Rotterdam, The Netherlands.

Copyright ${ }^{(-)} 1995$ by the American Academy of Dermatology, Inc. $0190-9622 / 95 \$ 3.00+0 \quad \mathbf{1 6} / \mathbf{1} / \mathbf{6 1 8 3 7}$ described after antigen presentation in the absence of costimulatory signals. ${ }^{5-7}$ In both mice ${ }^{8-21}$ and human beings, ${ }^{5,22}$ UVB induces specific hyporesponsiveness when administered simultaneously with allergen. UV exposure (even suberythemagenic doses) has significant down-modulatory effects on $T$ cellmediated responses to contact allergens. In a previous study we demonstrated a clear effect of UVB on patch test responses to nickel, possibly through depletion of Langerhans cells (LC) and induction of $\mathrm{CD}^{-} \mathrm{a}^{-} \mathrm{DR}^{+}$antigen-presenting cells. ${ }^{5}$

Until now, hyposensitization treatment has been restricted to immediate hypersensitivity reactions such as those to insect venoms and pollen. In view of the clear effects of UVB on LC and ACD, we designed a hyposensitization schedule that bypasses the highly sensitizing potential of epidermal LC by combining UVB treatment with subcutaneous injection of nickel sulfate solutions.

\section{MATERIAL AND METHODS \\ Patch tests}

Before the start of the study a European standard patch test series of contact allergens (van der Bend, Brielle, The 
Table I. Monoclonal antibodies used

\begin{tabular}{lll}
\hline \multicolumn{1}{c}{ Antibody } & $\begin{array}{c}\text { CD code } \\
\text { (antigen recognized) }\end{array}$ & \multicolumn{1}{c}{ Source } \\
\hline Leu-4 (FITC/PE) & CD3 & Becton Dickinson, Sunnyvale, Calif. \\
Leu-3 (FITC/PE) & CD4 & Becton Dickinson \\
Leu-1 & CD5 & Becton Dickinson \\
Leu-2 (PE) & CD8 & Becton Dickinson \\
LFA1/2 & CD11a & CLB, Amsterdam, The Netherlands \\
My4 & CD14 & Coulter Clone; Hialeah, Fla. \\
Leu-11c (PE) & CD16 & Becton Dickinson \\
B1 (FITC) & CD19 & Coulter Clone \\
B4 (FITC) & CD20 & Coulter Clone \\
2A3 (PE) & CD25 & Becton Dickinson \\
HLe-1 & CD45 & Becton Dickinson \\
BBA4 & CD54 & British Biotechnology, Oxon, U.K. \\
Leu-19 (PE) & CD56 & Becton Dickinson \\
L243 (PE) & HLA-DR & Becton Dickinson \\
\hline
\end{tabular}

$C L B$, Central Laboratory of the Red Cross Blood Transfusion Service; $F I T C$, fluorescein isothiocyanate; $L F A$, lymphocyte function-associated antigen; $P E$, phycoerythrin.

Netherlands), including nickel sulfate, potassium dichromate, and cobalt chloride, was performed according to guidelines of the International Contact Dermatitis Research Group. After 48 hours the patch chambers were removed. At 48 and 72 hours the skin reaction was scored as described earlier. ${ }^{23}$ At the start of the study patch tests with nickel, chromium, and cobalt were repeated to obtain baseline values. Because of the risk of further sensitization or boostering, patch tests were not repeated.

\section{Patients}

Twenty-one patients allergic to nickel as judged by history and clinical signs of contact allergy (predominantly on the hands and face) indicating nickel as a likely cause and confirmed by a patch test response of $2+$ or greater to nickel sulfate were enrolled in and completed the study. All subjects were nonpregnant women.

Each patient was randomly assigned to either the hyposensilized group, scheduled for UVB plus nickel sulfate administration, or to the control group, which was to receive only UVB treatment. The protocol and informed consent documents were approved by the committee on medical ethics of our hospital. The hyposensitized group consisted of 12 women, $28 \pm 5$ years of age. Nine patients, $38 \pm 16$ years of age, formed the control group.

\section{UVB treatment}

A Waldmann UV1000 standing UV cabinet was used for UV treatment. All patients (hyposensitized and control groups) received UVB pretreatment during the first 3 to 6 months. On the basis of skin type, exposure started at 5 to $10 \mathrm{~mJ} / \mathrm{cm}^{2}$ three times a week and gradually increased, allowing only mild erythema. Nickel sulfate injections were started in the hyposensitized group as soon as a cumulative dose of $1.0 \mathrm{~J} / \mathrm{cm}^{2}$ was reached. At this point, UV exposure was continued once a week until a cumulative dose of approximately $1.25 \mathrm{~mJ} / \mathrm{cm}^{2}$ was reached.

\section{Hyposensitization procedure}

Sterile, pyrogen-free solutions of $10^{-6}, 10^{-5}, 10^{-4}$, and $10^{-3} \mathrm{~mol} / \mathrm{L}$ nickel sulfate were prepared. The lowest concentration equals the nickel concentration normally measured in body fluids. ${ }^{24-27}$ In a manner similar to hyposensitization schedules used in type I allergy, weekly subcutaneous injections were started with $0.1 \mathrm{ml}$ of the lowest nickel sulfate concentration in the arm. After each injection the patients were observed for at least $20 \mathrm{~min}$ utes. If possible, the next doses were subsequently $0.2,0.4$, 0.7 , and $1.0 \mathrm{ml}$ of the same concentration, and finally 0.1 $\mathrm{ml}$ of the next concentration. Doses were increased until either minimal local symptoms occurred or the highest concentration was reached. At this point the maximal dose achieved was continued and the interval was gradually prolonged up to 1 month. The total duration of the nickel sulfate hyposensitization was 2 years.

\section{Clinical evaluation}

The clinical follow-up period was 24 months. At three defined time points-at the start of the study (month 0 ), at maximal UVB exposure (month 6), and at the end (month 18) of the hyposensitization treatment-clinical evaluation was done. The affected area of involved skin, severity (itching, papules, vesicles, and fissure formation), frequency of symptoms, therapeutic need (use of corticosteroids and its potency), and a subjective quality of life assessment were scored on a standard evaluation form. With respect to clinical scores, the control group consisted 

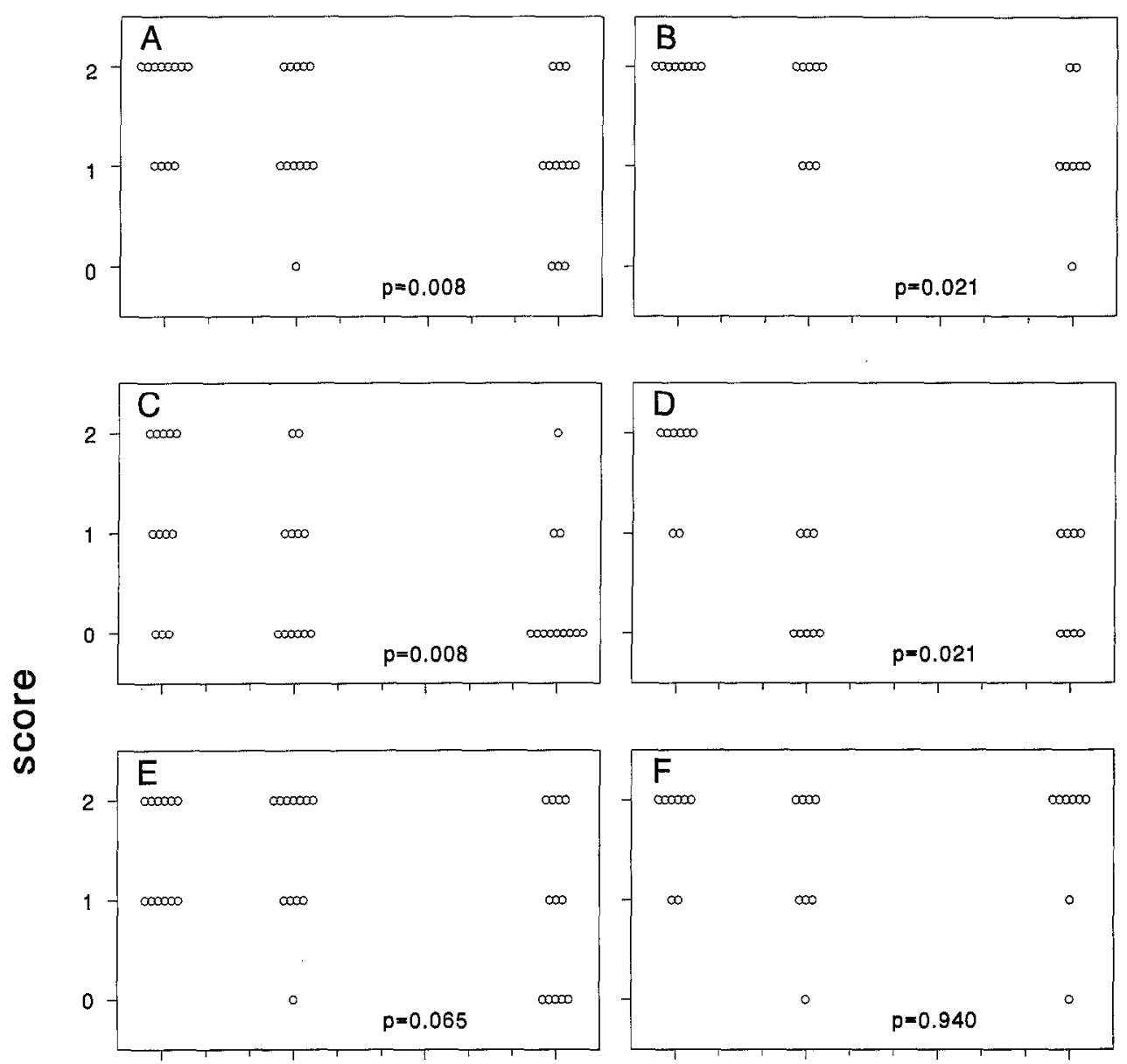

1
0
0

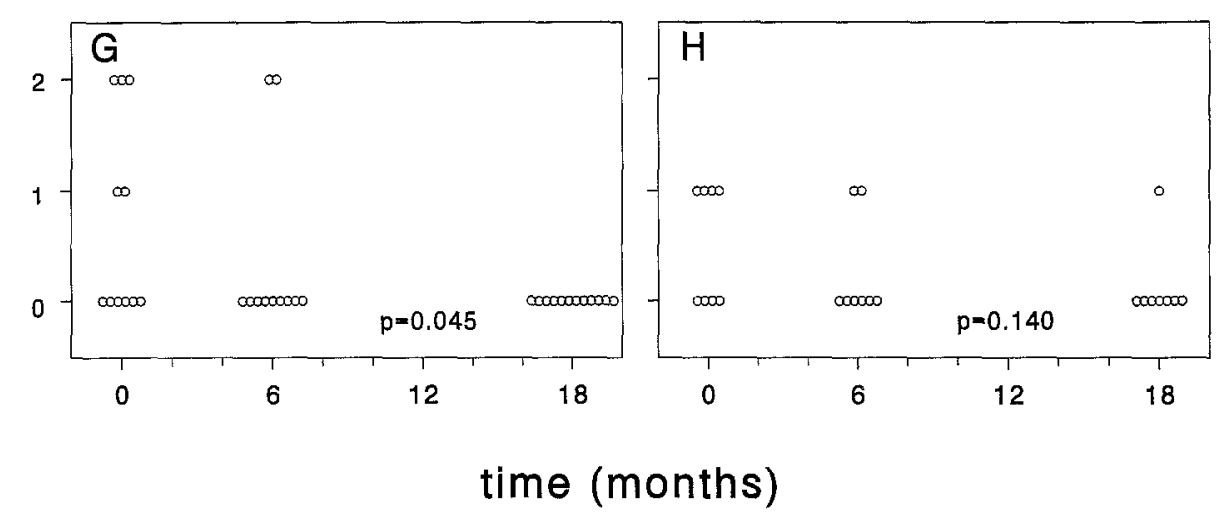

Fig. 1. Time course of disease activity scores in hyposensitized (left panels) and control (right panels) groups with regard to affected area $(A$ and $B)$, severity $(C$ and $D)$, frequency $(E$ and $F)$ and therapy $(G$ and $H$ ).

of eight patients, because we excluded one patient because of lack of clinical follow-up information.

\section{Lymphocyte proliferation assays}

Lymphocyte proliferation assays (LPA) were performed as described earlier. ${ }^{23}$ Lymphocyte proliferation was expressed as counts per minute. Stimulation indices (SI) (i.e., relative proliferation) were calculated by divid- ing specific by background proliferation. In our laboratory an SI greater than 3 was considered to be indicative of prior lymphocyte sensitization to nickel.

\section{Fluorescence-activated cell sorter immunophenotyping}

Peripheral blood samples were immunophenotyped with the monoclonal antibodies listed in Table I. Except 

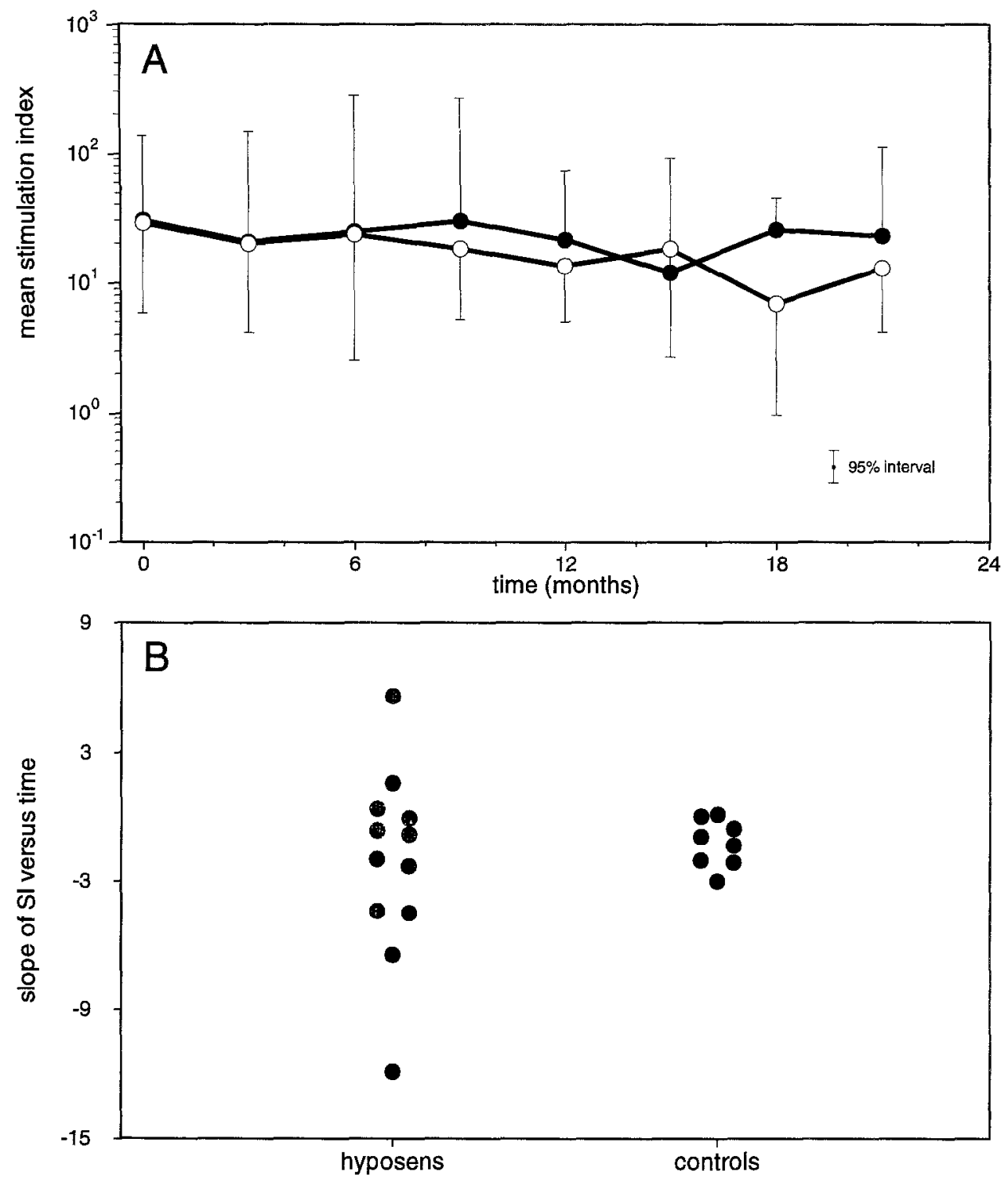

Fig. 2. Level of nickel reactivity in time as measured by nickel-specific lymphocyte proliferation. A, Mean SI values over time in all patients within each group. Bars represent $95 \%$ confidence intervals. B, Slopes of individual time plots as calculated by lincar regression analysis. Closed circles, hyposensitized group; open circles, control group.

for lymphocyte function-associated antigen (LFA)-1/2 and BBA4, all monoclonal antibodies were directly conjugated to either fluorescein isothiocyanate or phycoerythrin. Measurement and analysis was done with a FACScan flow cytometer (Becton Dickinson, San Jose, Calif.) with Simulset, FACScan, Consort 30, and Lysis research software (Becton Dickinson, San Jose, Calif.). Both absolute cell numbers per microliter and percentages were calculated.

\section{Statistical analysis}

Professional STATA 3.0 Statistics/Data Analysis (Computing Resource Center, Santa Monica, Calif.) and
EGRET (version 0.26.6, 1991, Serc and Cytel, Seattle, Wash.) were used for data analysis and statistical calculations.

The change of the disease activity scores during treatment was analyzed within each group with the Wilcoxon signed-rank test. An exact trend test was used to compare the hyposensitized and control groups with regard to the distribution of the scores at the end of the study.

The distributions of SI and cell counts were transformed to normal by taking natural log values. This enables use of parametric statistical methods. The resulting distributions were checked for normality in normal plots.

Linear regression was used to analyze time trends of 
Table II. Distribution of lymphocyte phenotypes

\begin{tabular}{|c|c|c|c|}
\hline \multirow[b]{2}{*}{ Cell type } & \multicolumn{2}{|c|}{ Nickel-allergic subjects } & \multirow[b]{2}{*}{ Nonallergic controls } \\
\hline & Hyposensitized & Control & \\
\hline Lymphocytes & $2.0(1.4-4.1)$ & $1.3(1.0-2.5)$ & $1.7(1.1-2.6)$ \\
\hline $\mathrm{B}$ cells & $0.2(0.08-0.4)$ & $0.1(0.05-0.2)$ & $0.1(0.1-0.2)$ \\
\hline $\mathrm{T}$ cells & $1.4(1.1-3.2)$ & $1.1(0.7-2.2)$ & $1.2(0.8-2.2)$ \\
\hline CD4 & $1.1(0.6-2.5)$ & $0.7(0.5-1.4)$ & $0.7(0.4-1.5)$ \\
\hline CD8 & $0.5(0.3-1.0)$ & $0.3(0.1-0.7)$ & $0.4(0.2-0.7)$ \\
\hline Natural killer cells & $0.2(0.08-0.3)$ & $0.1(0.1-0.2)$ & $0.2(0.06-0.6)$ \\
\hline
\end{tabular}

Values are median absolute cell counts per milliliter; $95 \%$ confidence intervals shown in parentheses.

lymphocyte proliferation and activated T-cell numbers during treatment. ${ }^{28}$ The resulting slope values of both groups were compared in a $t$ test modified for unequal variances (Welch test). Equality of variances was tested in the variance ratio test ( $F$ test).

\section{RESULTS}

\section{Baseline values of patch tests and LPA}

The distributions of baseline values for both patch tests and LPA in the hyposensitized and control groups were compared. Patch test scores and specific lymphocyte proliferation were comparable in both groups. In both the hyposensitized and the control groups a patient previously (before study) patch test reactive to nickel showed a negative baseline value of the patch test at the start of treatment. However, LPA results showed that lymphocyte reactivity to nickel still existed.

\section{UVB dose}

Individual UVB doses ranged between 5 and 50 $\mathrm{mJ} / \mathrm{cm}^{2}$. In both groups the cumulative dose of 1.0 $\mathrm{J} / \mathrm{cm}^{2}$ was reached within the first 4 months.

\section{Nickel sulfate administration}

Most patients tolerated a 100 - to 1000 -fold increase of the nickel dose within 3 months. In two patients the maximum dose of $1.0 \mathrm{ml}$ of $10^{-3} \mathrm{~mol} / \mathrm{L}$ nickel sulfate was reached. Adverse effects remained limited to transient local induration that developed at the site of injection within 8 to 24 hours. These lesions were histologically characterized by a perivascular accumulation of mononuclear cells. To avoid this reaction, doses were temporarily lowered. As a result, in some patients doses varied, occasionally by 10-fold, because of variable nickel tolerability.

\section{Clinical evaluation}

Fig. 1 shows dot plots of the four disease activity scores in both groups at three time points: at the start of the study (month 0 ), during maximal UVB exposure (month 6), and at the end of the study (month 18). Overall, scores within both groups dropped during UVB treatment. This trend continued even after UVB exposure was stopped. In the hyposensitized group this led to $p$ values of $0.0076,0.0076$, 0.065 , and 0.045 for the affected area, severity, frequency, and therapy scores respectively. In the control group these $p$ values were larger, namely, 0.021 , $0.021,0.94$, and 0.14 , respectively. The change of the disease activity scores was most evident for the affected area and severity scores. However, between the hyposensitized and control groups no statistically significant score differences were found ( $p=0.84$, $0.33,0.26$, and 0.40 , respectively).

\section{Lymphocyte proliferation}

Specific lymphocyte reactivity against nickel was monitored during the hyposensitization therapy. Within each patient some variation of SIs was found during the 2-year observation period. Neither SI nor net counts per minute values showed significant correlation with clinical scores.

In Fig. 2, $A$, mean SI values and 95\% confidence intervals of all patients within each group are plotted against duration of treatment. Mean proliferation indices over time varied between 10 and 30 . No significant difference was seen between the groups. In an attempt to characterize further the time course of lymphocyte reactivity, slopes of individual time plots were calculated by linear regression analysis. The resulting slope values indicate ascending or descending trends of lymphocyte reactivity with duration of treatment. However, neither positive nor negative slope values corresponded with clinical improvement. Fig. 2, $B$, shows approximately equivalent mean slope values but increased slope variance in the hyposensitized group as compared with control subjects. This difference of variances was highly significant $(p<0.001)$. 

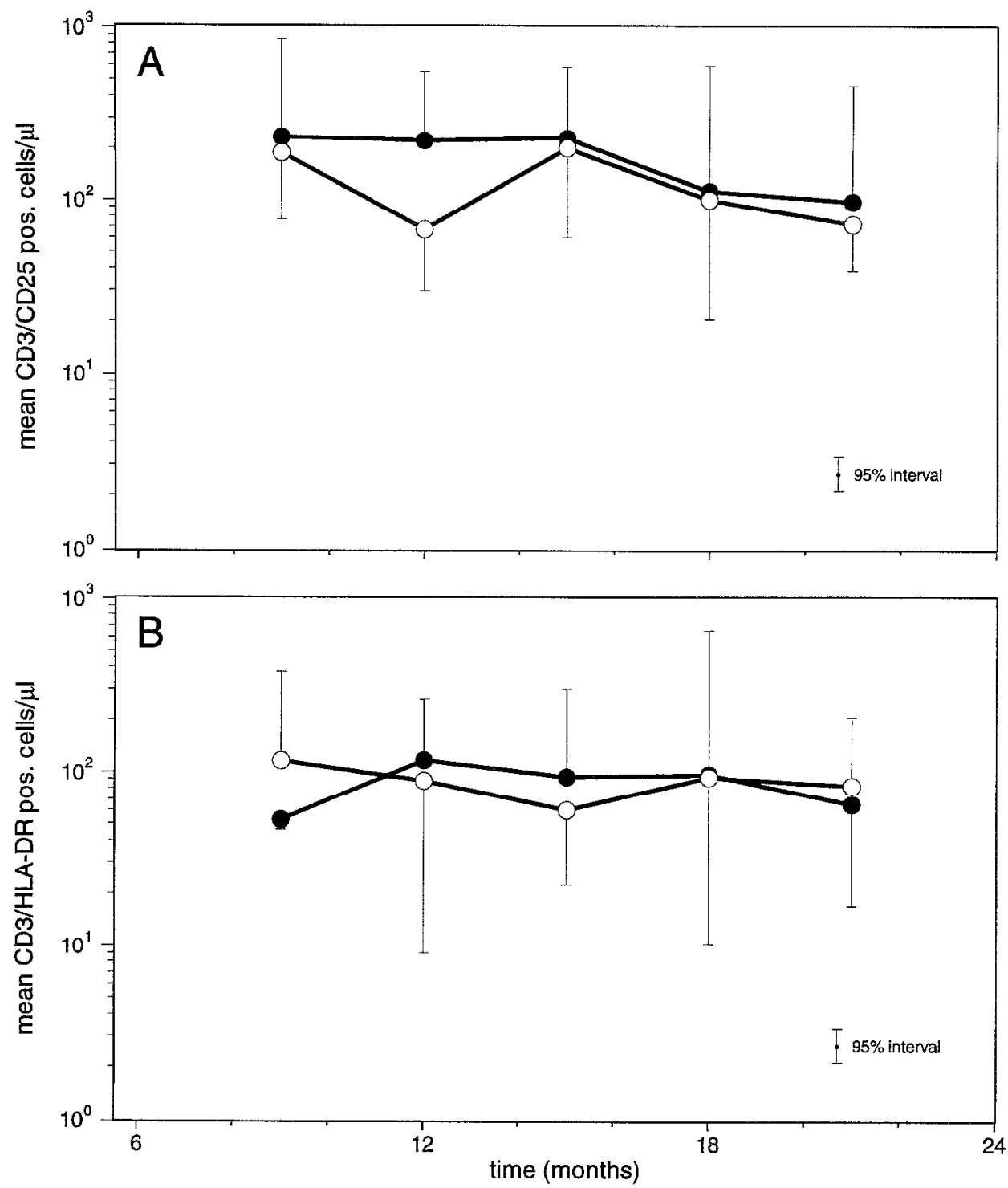

Fig. 3. Mean CD3+/IL-2 receptor $+(\mathbf{A})$ and $C D 3+/ H L A-D R+(\mathbf{B})$ cell numbers over time in all patients within each group. Bars represent $95 \%$ confidence intervals. Closed circles, hyposensitized group; open circles, control group.

\section{Fluorescence-activated cell sorter immunophenotyping}

Numbers of B cells, T cells (including the subpopulations), and natural killer cells were within normal limits, comparable in both groups, and fairly constant over time (Table II).

In an attempt to characterize further the nickelreactive lymphocytes, we did flow cytometric analysis of peripheral blood mononuclear cells for activated $T$ cells with CD3/HLA-DR and CD3/CD25 double staining. Actual double-positive cell numbers per microliter were calculated and plotted against time. Values ranged from 10 to 1000 cells $/ \mu$ in both groups. Fig. 3 shows the time course of mean
$\mathrm{CD}^{+} / \mathrm{IL}-2$ receptor ${ }^{+}$and $\mathrm{CD}^{+} / \mathrm{HLA}^{-\mathrm{DR}^{+}}$cell counts and $95 \%$ confidence intervals of all patients within each group. On average, $\mathrm{CD} 25^{+}$counts were 1.7 times higher than HLA-DR ${ }^{+}$counts. As previously described, ${ }^{29}$ coexpression of IL-2 receptor and HLA-DR on T cells is limited. Apparently these markers represent at least partially different types or phases of activation. The average number of activated $T$ cells was estimated at approximately 100 to 150 cells $/ \mu$ l (i.e., $5 \%$ to $20 \%$ of circulating T cells). These values are within normal limits.

LFA- $1 \alpha$ and intercellular adhesion molecule-1 expression of both peripheral blood lymphocytes and monocytes was also measured. Lymphocytes showed 
a bimodal LFA- $1 \alpha$ expression, that is, normal $\left(\mathrm{LFA}_{-1}{ }^{+}\right.$) and high (LFA-1 ${ }^{++}$), mainly because of the expression of this molecule on T cells. During the study these two levels of expression appeared to be inversely correlated. These time trends, however, did not match clinical disease activity.

\section{DISCUSSION}

Hyposensitization with contact allergens has previously been shown to be effective. ${ }^{30-34}$ The present study describes monitoring of clinical and immunologic features during such nickel hyposensitization.

Considerable clinical improvement was observed during UVB pretreatment. In both groups this trend persisted even after UVB withdrawal. No statistically significant difference between the groups was seen.

Lymphocyte reactivity to nickel appeared to fluctuate with time. Height of SI showed no correlation with clinical scores. Discordance between clinical and in vitro findings has previously been described. ${ }^{35-40}$

Overall, no significant change in the in vitro lymphocyte reactivity to nickel was seen during the monitored period. However, time-trend analysis of each patient revealed a significantly larger slope variability within the hyposensitized group. Its meaning is not entirely clear. Possibly the effect of hyposensitization varies in different persons. ${ }^{21,41}$ Activated $\mathrm{T}$ lymphocytes in peripheral blood, measured as $\mathrm{CD}^{+} / \mathrm{HLA}^{-\mathrm{DR}^{+}}$and $\mathrm{CD}^{+} / \mathrm{CD} 25^{+}$ cells, remained within normal limits during treatment. It is conceivable that the number of nickelspecific memory T lymphocytes is too low to allow detection of changes in the peripheral circulation.

As in type I hyposensitization, the mechanisms by which clinical improvement might be cxplaincd rcmain to be elucidated. Evidence is emerging that besides $\mathrm{LC}$ and $\mathrm{T}$ lymphocytes, keratinocytes are also actively involved in immunologic reactions in the skin. Insight into the process of induction of central or peripheral tolerance, clonal anergy, or active suppression is only beginning to appear. ${ }^{42-45}$ Analysis of epidermal cells and lymphocytes for the presence and susceptibility of costimulatory factors, such as adhesion molecules ${ }^{46-48}$ and cytokines, ${ }^{7,49,50}$ and the influence of immunomodulators such as UV radiation on these, may provide more insight into this process.

We thank Rene van den Beemd, Lidy GeursenReitsma, and Tar van Os for their assistance in fluores- cence-activated cell sorter analysis, patch testing, and preparation of the graphs, respectively.

\section{REFERENCES}

1. Sinigaglia F, Scheidegger D, Garotta G, et al. Isolation and charactcrization of $\mathrm{Ni}$-spccific $\mathrm{T}$ cell clones from paticnts with Ni-contact dermatitis. J Immunol 1985;135:3929-32.

2. Kapsenberg ML, Van der Pouw-Kraan T, Stiekema FE, et al. Direct and indirect nickel-specific stimulation of T lymphocytes from patients with allergic contact dermatitis to nickel. Eur J Immunol 1988;18:977-82.

3. Romagnoli P, Labhardt AM, Sinigaglia F. Selective interaction of Ni with an MHC-bound peptide. EMBO J 1991;10:1303-6.

4. Kapsenberg ML, Wierenga EA, Stiekema FEM, et al. Th1 lymphokine production profiles of nickel-specific CD4+ T-lymphocyte clones from nickel contact allergic and nonallergic individuals. J Invest Dermatol 1992;98:59-63.

5. Cooper KD, Oberhelman L, Hamilton TA, et al. UV exposure reduces immunization rates and promotes tolerance to epicutaneous antigens in humans: relationship to dose, CDla-DR+epidermal macrophage induction, and Langerhans cell depletion. Proc Natl Acad Sci USA 1992;89:8497501.

6. Peguet-Navarro J, Dalbiez-Gauthier C, DezutterDambuyant $\mathrm{C}$, et al. Dissection of human Langerhans cells' allostimulatory function: the need for an activation step for full development of accessory function. Eur J Immunol 1993;23:376-82.

7. Enk $A H$, Angeloni VC, Udey MC, et al. Inhibition of Langerhans cell antigen-presenting function by IL-10. J Immunol 1993;151:2390-8.

8. Kripke ML. Immunological unresponsiveness induced by ultraviolel radiation. Immunol Rev 1984;80:87-102.

9. Kripke ML, McClendon E. Studies on the role of antigenpresenting cells in the systemic suppression of contact hypersensitivity by UVB radiation. J Immunol 1986;137: 443-7.

10. Tokura $Y$, Miyachi $Y$, Takigawa M, et al. Ultraviolct-induced suppressor $T$ cells and factor(s) in murine contact photosensitivity: I. biological and immunochemical characterization of factor(s) extracted from suppressor $\mathrm{T}$ cells. Cell Immunol 1987;1 10:305-20.

11. Harriott-Smith TG, Halliday WJ. Production of suppressor factors induced by ultraviolet irradiation or cis-urocanic acid requires Lyt-2+ lymphocytes. Immunol Cell Biol 1988;66:313-8.

12. Fisher MS, Menter JM, Willis I. Ultraviolet radiation-induced suppression of contact hypersensitivity in relation to padimate $\mathrm{O}$ and oxybenzone [Comments]. J Invest Dermatol 1989;92:337-41.

13. Oluwole SF, Reemtsma K, Hardy MA. Characteristics and function of suppressor $\mathrm{T}$ lymphocytes in immunologically unresponsive rats following pretreatment with UV-Birradiated donor leukocytes and peritransplant cyclosporine. Transplantation 1989;47:1001-7.

14. Tokura Y, Takigawa M, Satoh T, et al, Ultraviolet-induced suppressor $\mathrm{T}$ cells and factor(s) in murine contact photosensitivity: II. Igh-V restriction of T-cell-suppressor factor. Clin Immunol Immunopathol 1989;51:83-90.

15. Satoh T, Tokura Y, Satoh Y, et al. Ultraviolet-induced suppressor $\mathrm{T}$ cells and factor(s) in murine contact photosensitivity: III. mode of action of T-cell-suppressor factor(s) and interaction with cytokines. Cell Immunol 1990;131: $120-31$. 
16. Vandekerckhove BA, Datema G, Claas FH. Immunological unresponsiveness induced by ultraviolet-B-irradiated and nonirradiated skin grafts. Transplantation 1990;49: 596-9.

17. Kim TY, Kripke ML, Ullrich SE. Immunosuppression by factors released from UV-irradiated epidermal cells: selective effects on the generation of contact and delayed hypersensitivity after exposure to UVA or UVB radiation. J Invest Dermatol 1990;94:26-32.

18. Glass M, Bergstresser PR, Tigelaar RE, et al. UVB radiation and DNFB skin painting induce suppressor cells universally in mice. J Invest Dermatol 1990:94:273-8.

19. Simon JC, Tigelaar RE, Bergstresser PR, et al. Ultraviolet $B$ radiation converts Langerhans cells from immunogenic to tolerogenic antigen-presenting cells: induction of specific clonal anergy in CD4+ $\mathrm{T}$ helper 1 cells. $\mathrm{J}$ Immunol 1991;146:485-91.

20. Aubin F, Kripke ML, Ullrich SE. Activation of keratinocytes with psoralen plus UVA radiation induces the release of soluble factors that suppress delayed and contact hypersensitivity. I Invest Dermatol 1991;97:995-1000.

21. Kurimoto I, Streilein JW.Studies of contact hypersensitivity induction in mice with optimal sensitizing doses of hapten. J Invest Dermatol 1993;101:132-6.

22. Prens EP, Benne $K$, van Joost $T$, et al. UVB treatment induces decreased patch test responses and in vitro lymphocyte proliferation to nickel sulphate in nickel allergic patients. In: Passchier WF, Bosnjakovic BFM, ed. Human exposure to ultraviolet radiation: risks and regulation. Amsterdam, The Netherlands: Elsevier, 1987:117-20.

23. Prens EP, Benne $K$, van Joost T, et al. Differential role of lymphocyte function-associated antigens in the activation of nickel-specific peripheral blood $\mathrm{T}$ lymphocytes. J Invest Dermatol 1991;97:885-91.

24. Spruit D, Bongaarts PJM. Nickel content of plasma, urine and hair in contact dermatitis. Dermatologica 1977;154: 291-300.

25. Maibach HI, Nickel. In: Maibach HI, Menne T, eds. Nickel and skin: immunology and toxicology. Florida: CRC Press, 1989:1-7.

26. Santucci B, Manna F, Cristaudo A, et al. Serum concentrations in nickel-sensitive patients after prolonged oral administration. Contact Dermatitis 1990;22:253-6

27. Santucci B, Manna F, Cannistraci C, et al. Serum and urine concentrations in nickel-sensitive patients after prolonged oral administration. Contact Dermatitis 1994;30:97-101.

28. Matthews JNS, Altman DG, Campbell MJ, et al. Analysis of serial measurements in medical research. Br Med J 1990;300:230-5.

29. Karttunen R, Silvennoinen-Kassinen S, Juutinen K, et al. Nickel antigen induces IL-2 secretion and IL-2 receptor expression mainly on CD4+ $\mathrm{T}$ cells, but no measurable gamma interferon secretion in peripheral blood mononuclear cell cultures in delayed type hypersensitivity to nickel. Clin Exp Immunol 1988;74:387-91.

30. Sjovall P, Christensen OB, Moller H. Oral hyposensitization in nickel allergy. J AM ACAD DERMATOL 1987;17: 774-8.

31. Reginella RF, Fairfield JC, Marks JGJ. Hyposensitization to poison ivy after working in a cashew nut shell oil processing factory. Contact Dermatitis 1989;20:274-9.

32. Friedmann PS. The immunology of allergic contact dermatitis: the DNCB story. Adv Dermatol 1990;5:175-95.
33. van Hoogstraten I. Oral induction of immunological tolerance for nickel and chromium: prevention of allergic contact hypersensitivity [Dissertation]. Amsterdam, The Netherlands: Free University Amsterdam; 1992.

34. Revillard JP, Cozon G, Czerkinsky C. Oral administration of immunomodulators and the mucosal immune system. Dev Biol Stand 1992;77:31-7.

35. Nordlind K. Further studies on the lymphocyte transformation test in diagnosis of nickel allergy: effect of fractionation of lymphocytes into different subpopulations on the basis of density. Int Arch Allergy Appl Immunol 1984;75: 333-6.

36. Nordlind K. Lymphocyte transformation test in diagnosis of nickel allergy: a comparison between the separation of peripheral blood lymphocytes on Ficoll-Paque, Percoll, or by gravity sedimentation. Int Arch Allergy Appl Immunol 1984;73:151-4.

37. Al Tawil NG, Berggren G, Emtestam L, et al. Correlation between quantitative in vivo and in vitro responses in nickel-allergic patients. Acta Derm Venereol (Stockh) 1985; $65: 385-9$

38. von Blomberg-van der Flier M, van der Burg CK, Pos O, et al. In vitro studies in nickel allergy: diagnostic value of a dual parameter analysis. J Invest Dermatol 1987;88: 362-8.

39. Everness KM, Gawkrodger DJ, Botham PA, et al. The discrimination between nickel-sensitive and non-nickel-sensitive subjects by an in vitro lymphocyte transformation test. Br J Dermatol 1990;122:293-8.

40. Rasanen L, Tuomi ML. Diagnostic value of the lymphocyte proliferation test in nickel contact allergy and provocation in occupational coin dermatitis. Contact Dermatitis 1992 27:250-4.

41. Santucci B, Cristaudo A, Cannistraci C, et al. Nickel sensitivity: effects of prolonged oral intake of the element Contact Dermatitis 1988;19:202-5.

42. Goodnow CC. B-cell tolerance. Curr Opin Immunol 1992;4:703-10.

43. Kroemer G, Martinez C. Mechanisms of self tolerance. Immunol Today 1992;13:401-4.

44. Nossal GJ. Cellular and molecular mechanisms of B lymphocyte tolerance. Adv Immunol 1992;52:283-331.

45. McCarthy NJ, Smith CA, Williams GT. Apoptosis in the development of the immune system: growth factors, clonal selection and bcl-2. Cancer Metastasis Rev 1992;11:15778 .

46. Tang A, Udey MC. Inhibition of epidermal Langerhans cell function by low dose ultraviolet B radiation. J Immunol 1991;146:3347-55.

47. Tang A, Udey MC. Doses of ultraviolet radiation that modulate accessory cell activity and ICAM-1 expression are ultimately cytotoxic for murine epidermal Langerhans cells. J Invest Dermatol 1992;99:71-3.

48. Krutmann J, Trefzer U. Modulation of the expression of intercellular adhesion molecule-1 (ICAM-1) in human keratinocytes by ultraviolet (UV) radiation. Springer Semin Immunopathol 1992;13:333-44.

49. Fiorentino DF, Zlotnik A, Vieira $\mathbf{P}$, et al. IL-10 acts on the antigen-presenting cell to inhibit cytokine production by Th1 cells. J Immunol 1991;146:3444-51.

50. van Wilsem E, Breve J, van Hoogstraten I, et al. The influence of dendritic cells on T-cell cytokine production. Adv Exp Med Biol 1993;329:111-5. 